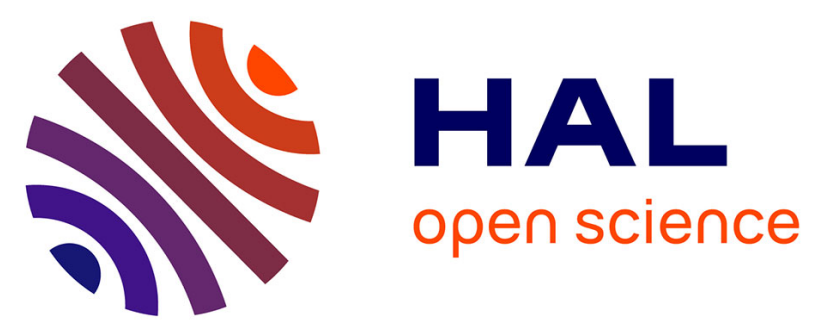

\title{
Design, fabrication and anti-aging behavior of a multifunctional inorganic--organic hybrid stabilizer derived from co-intercalated layered double hydroxides for polypropylene
}

Qian Zhang, Yixuan Guo, Adam Marek, Vincent Verney, Fabrice Leroux, Pinggui Tang, Dianqing Li, Yongjun Feng

\section{To cite this version:}

Qian Zhang, Yixuan Guo, Adam Marek, Vincent Verney, Fabrice Leroux, et al.. Design, fabrication and anti-aging behavior of a multifunctional inorganic-organic hybrid stabilizer derived from co-intercalated layered double hydroxides for polypropylene. Inorganic Chemistry Frontiers, 2019, 6

(9), pp.2539-2549. 10.1039/C9QI00601J . hal-02286152

\section{HAL Id: hal-02286152 \\ https://hal.science/hal-02286152}

Submitted on 20 Nov 2020

HAL is a multi-disciplinary open access archive for the deposit and dissemination of scientific research documents, whether they are published or not. The documents may come from teaching and research institutions in France or abroad, or from public or private research centers.
L'archive ouverte pluridisciplinaire HAL, est destinée au dépôt et à la diffusion de documents scientifiques de niveau recherche, publiés ou non, émanant des établissements d'enseignement et de recherche français ou étrangers, des laboratoires publics ou privés. 


\title{
Design, Fabrication and Anti-aging Behavior of Multifunctional Inorganic- Organic Hybrid Stabilizer Derived from Co-intercalated Layered Double Hydroxides for Polypropylene
}

\begin{abstract}
Qian Zhang, ${ }^{a}$ Yixuan Guo, ${ }^{a}$ Adam A. Marek, ${ }^{b}$ Vincent Verney, ${ }^{b}$ Fabrice Leroux, ${ }^{* b}$ Pinggui Tang, ${ }^{a}$ Dianqing Li $^{\mathrm{a}}$ and Yongjun Feng*

It is of great and increasing interest to develop multifunctional additives to enhance anti-aging performance of polypropylene (PP) and then enlarge its application fields. Here, hindered amine light stabilizer ( $\mathrm{H}$ for HALS) and hindered phenolic antioxidant (D for DBHP) with low molecular weight were co-intercalated into layered double hydroxides (LDH) in a coprecipitation route to produce a series of inorganicorganic hybrid materials $Z n_{2} A l-H_{x} D_{y}-L D H$, adjusting the anions ratio $(x+y=1$ and $x: y=0: 1,1: 0,1: 1,2: 1,1: 2)$. Subsequently, hybrid material LDH fillers (HALS-LDH, DBHP-LDH, $\left.H_{x} D_{y}-L D H,(H-L D H)_{x}(D-L D H)_{y}\right)$, used as anti-aging agents, were successively dispersed into PP by two methods: solvent mixing/casting and extrusion mixing. The corresponding crystalline structure, morphological, rheological properties as well as thermal and light oxidative degradation behaviour were carefully investigated using various techniques such as XRD, TEM and rheology. The results showed that the LDH fillers were well dispersed into PP without any influence on its crystallization behavior and provided a chain extension effect on PP, this even more pronounced for $H_{x} D_{y}-L D H$. The thermal stability of $H_{x} D_{y}-L D H / P P$ composites ( $x: y=$ 1:1, 2:1, 1:2) are significantly improved, compared with that of another composites. Moreover, through the accelerated aging test, the cointercalated hybrid material $\mathrm{H}_{x} \mathrm{D}_{y}-\mathrm{LDH}$ significantly inhibited the oxidative degradation of PP (thermal-aging and light-aging). The concomitant presence of HALS/DBHP co-intercalated within LDH structure strongly improved the anti-aging performance for PP. Therefore, such co-intercalated I/O hybrid adaptive system as a multifunctional additive agent opens potential future research for high-performance PP associated with hybrid fillers.
\end{abstract}

\section{Introduction}

Polypropylene (PP) as one kind of thermoplastic polymers has developed to be the second-most widely produced commodity plastic and therefore is exposed to an increasing requirement and technical demands in various fields, particularly in packaging, labeling, and automobile. In 2017, the global production was ca. 70 million tons. ${ }^{1}$ However owing to the bonding $\alpha-\mathrm{H}$ in its molecular structure, PP suffers from seriously thermal- and photo-degradation at environmental temperature beyond $100{ }^{\circ} \mathrm{C}$ and under UV exposure. ${ }^{2}$ Therefore, various kinds of functional additives are added into PP during the melting process to enhance the application performance, for example, light stabilizers, antioxidants, antistatic agents and fire retardants. ${ }^{3-5}$ Among them, hindered amine light stabilizers (HALS) and hindered phenolic antioxidants (HPA) have shown outstanding performance and have evidently been largely used in industry, containing 2,2,6,6- tetramethyl piperidine and 2,6di-tert-butylphenol functional group, respectively. ${ }^{6,7}$ The active site in the HALS and HPA structure is $-\mathrm{NH}-$ and $-\mathrm{OH}$, respectively, which captures the peroxyl radicals ROO produced during the oxidative degradation of PP, and thereby terminates oxidation chains. ${ }^{8,9}$ Particularly, the combination of HALS and HPA in PP exhibits the positively synergistic antiaging effect. ${ }^{10,11}$ Yet, two challenges remain for making full applicative use of the synergistic effect to produce high-performance PP by incorporation of multicomponent additives: (1) to lower as possible the high migration of organic anti-aging additives because of high compatibility between the additives and the PP; ${ }^{12}(2)$ to increase significantly the low dispersion of two compounds in PP. ${ }^{13}$

High migration of the additives from PP during the service life does not only directly result in the fast loss of application performance, but also lead to the ingress of leached additives out of the polymer that may threaten the safety in terms of environment and health concerns. To date, two typical approaches have been developed to overcome this issue: (1) increasing the corresponding molecular weight, ${ }^{14}$ and (2) immobilizing on the PP chains or inorganic particles such as $\mathrm{SiO}_{2}, \mathrm{CNTs}, \mathrm{GO} .{ }^{15-17}$ Undoubtedly, these two solutions do increase the synthesis cost of the additives making them unfeasible at large scale for PP. Besides, two components are more difficult to be highly dispersed in 
the PP, related to a single one. It is possible to simultaneously fix both above issues by cointercalation of HALS and HPA active species into the interlayer region of single layered double hydroxides (LDH) to develop single-composition multifunctional anti-aging additives.

Layered double hydroxides (LDH), as one important inorganic host material, has attracted increasing attention for various kinds of functional materials by intercalation and surface immobilization in polymer, ${ }^{18,19}$ catalysis, ${ }^{20}$ environment, ${ }^{21}$ electrochemistry, ${ }^{22}$ and biology, etc.... ${ }^{23}$ More recently, some interesting multifunctional additives have been explored by co-intercalation of different active species into the interlayer region of LDHs, and exhibited more excellent application performance related to the corresponding active species themselves due to the synergistic effect between the active species and the LDH host. ${ }^{24,25}$ In the intercalated LDH, the interaction between the host sheet and the guest species effectively anchors the active species and then hinders their migration out of the LDH vessel. ${ }^{26}$ Additionally the interface effects between the inorganic LDH host sheet and the PP chains reduce the motion of the intercalated $\mathrm{LDH}^{27}$ Besides, two active species with adjustable ratios are intercalated into the interlayer region of LDH to produce novel intercalated additive in a single composition, this has never been reported so far, and it is observed here to favorably enhance the dispersion of the additives in PP.

In this work, we designed and fabricated a series of novel inorganic/organic ( $1 / 0)$ hybrid materials $\mathrm{Zn}_{2} \mathrm{Al}-\mathrm{H}_{\mathrm{x}} \mathrm{D}_{\mathrm{y}}-\mathrm{LDH}(\mathrm{x}+\mathrm{y}=1$ and $\mathrm{x}: \mathrm{y}=0: 1,1: 0,1: 1,2: 1,1: 2)$ by co-intercalating the low molecular weight HALS and the HPA as the active species into LDHs, ${ }^{28,29}$ prepared a series of LDH/PP composites by both solvent or extrusion mixings using $\mathrm{Zn}_{2} \mathrm{Al}-\mathrm{H}_{\mathrm{x}} \mathrm{D}_{\mathrm{y}}-\mathrm{LDH}$ as the anti-aging nanofiller, and carefully investigated the oxidative degradation behavior (thermo- and light-oxidative) of LDH/PP composites as well as the structure-performance relationship. Scheme 1 describes the synthesis process of $Z n_{2} \mathrm{Al}-$ $\mathrm{H}_{\mathrm{x}} \mathrm{D}_{\mathrm{y}}-\mathrm{LDH}$ and $\mathrm{Zn}_{2} \mathrm{Al}-\mathrm{H}_{\mathrm{x}} \mathrm{D}_{\mathrm{y}}$-LDH/PP composites, where $\mathrm{H}$ presents the hindered amine light stabilizer such as 4-oxo-4-((2,2,6,6-tetramethylpiperidin-4-yl)amino)butanoic acid (HALS) and D does for the hindered phenolic antioxidant such as 3-(3,5-ditertbutyl-4-hydroxyphenyl) propionic acid (DBHP).

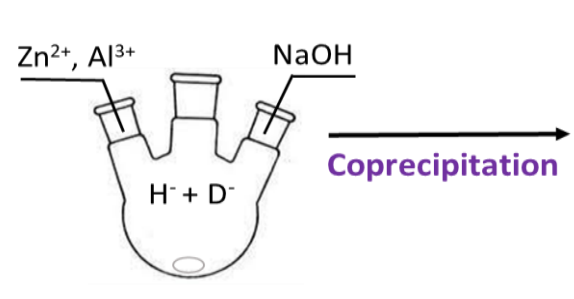

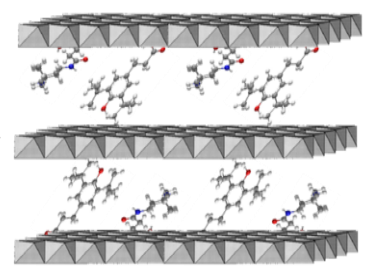

$\mathrm{Zn}_{2} \mathrm{Al}-\mathrm{H}_{\mathrm{x}} \mathrm{D}_{\mathrm{y}}-\mathrm{LDH}$ a. Solvent mixing.

b. Extrusion mixing

Polymer (PP)

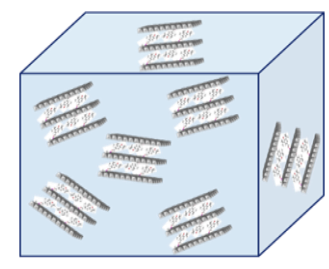

$\mathrm{Zn}_{2} \mathrm{Al}-\mathrm{H}_{\mathrm{x}} \mathrm{D}_{\mathrm{y}}-\mathrm{LDH} / \mathrm{PP}$ composites

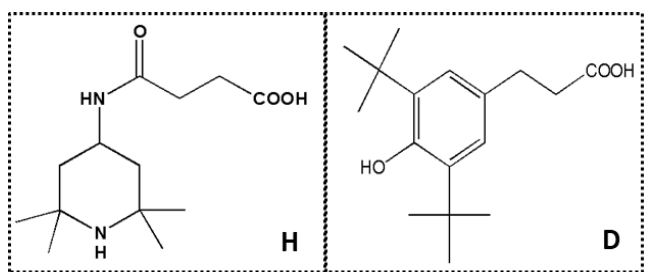

Scheme 1. Synthesis process of $\mathrm{Zn}_{2} \mathrm{Al}-\mathrm{H}_{\mathrm{x}} \mathrm{D}_{\mathrm{y}}-\mathrm{LDH}$ and $\mathrm{Zn}_{2} \mathrm{Al}-\mathrm{H}_{\mathrm{x}} \mathrm{D}_{\mathrm{y}}-\mathrm{LDH} / \mathrm{PP}$ composites, where $\mathrm{H}$ represents 4-oxo-4((2,2,6,6-tetramethylpiperidin-4-yl)amino)butanoic acid (HALS), and D does 3-(3,5-ditertbutyl-4-hydroxyphenyl) propionic acid (DBHP).

\section{Experimental Section}

\subsection{Chemicals}

The reagent grade materials, e.g., $\mathrm{Zn}\left(\mathrm{NO}_{3}\right)_{2} \cdot 6 \mathrm{H}_{2} \mathrm{O}, \mathrm{Al}\left(\mathrm{NO}_{3}\right)_{3} \cdot 9 \mathrm{H}_{2} \mathrm{O}, \mathrm{NaOH}$, xylene, hexane, ethanol and acetone, all commercially available, were A.R. grade and used as received. Polypropylene (Type: PP1300, melting point: 164-170 ${ }^{\circ} \mathrm{C}$; melting index: $1.5 \mathrm{~g} / 10 \mathrm{~min}$; density: $0.91 \mathrm{~g} / \mathrm{cm}^{3}$ ) were provided by Sinopec Beijing Yanshan Company. Deionized water was used through all the experiments. The detailed synthesis of HALS and DBHP were individually 
reported in our previous work: HALS was prepared from the addition reaction of tetramethylpiperidinamine and succinic anhydride; ${ }^{28}$ DBHP was obtained from the hydrolytic reaction of Irganox $1010 .^{29}$

\subsection{Synthesis of $\mathrm{Zn}_{2} \mathrm{Al}-\mathrm{H}_{\mathrm{x}} \mathrm{D}_{\mathrm{y}}-\mathrm{LDH}$ nanofillers}

A series of the HALS (H) and DBHP (D) co-intercalated $\mathrm{Zn}_{2} A \mathrm{Al}-\mathrm{H}_{\mathrm{x}} \mathrm{D}_{\mathrm{y}}-\mathrm{LDHs}(\mathrm{x}: \mathrm{y}=0: 1,1: 0,1: 1,2: 1,1: 2$ ) were prepared using the one-step coprecipitation method. Typically, for $\mathrm{Zn}_{2} \mathrm{Al}-\mathrm{H}_{1} \mathrm{D}_{1}-\mathrm{LDH}, \mathrm{HALS}(0.4557 \mathrm{~g}, 1.8 \mathrm{mmol})$ and DBHP (0.4948 g, $1.8 \mathrm{mmol}$ ) were solubilized in $50 \mathrm{~mL}$ of water containing $3.6 \mathrm{mmol} \mathrm{NaOH} ; 0.5295 \mathrm{~g}$ (1.8 mmol) of $\mathrm{Zn}\left(\mathrm{NO}_{3}\right)_{2} \cdot 6 \mathrm{H}_{2} \mathrm{O}$ and $0.3339 \mathrm{~g}(0.9 \mathrm{mmol})$ of $\mathrm{Al}\left(\mathrm{NO}_{3}\right)_{3} \cdot 9 \mathrm{H}_{2} \mathrm{O}$ were dissolved in $50 \mathrm{~mL} \mathrm{H}_{2} \mathrm{O}$ to form metal-salt solution. At room temperature, salt solution and $0.5 \mathrm{M} \mathrm{NaOH}$ solution were simultaneously added dropwise to the prepared HALS/DBHP solution under vigorous stirring and nitrogen atmosphere. The $\mathrm{pH}$ was maintained constant at $9.5( \pm 0.1)$ in the reaction system. The resulting white precipitate was aged for another $4 \mathrm{~h}$, afterwards centrifuged and washed twice with distilled water. Part of the $\mathrm{Zn}_{2} \mathrm{Al}-\mathrm{H}_{1} \mathrm{D}_{1}-\mathrm{LDH}$ slurry was dried at $40{ }^{\circ} \mathrm{C}$ to get the resulting powder for structural analysis. The remaining slurry washed with $\mathrm{EtOH} / \mathrm{H}_{2} \mathrm{O}$ mixture $(50 / 50, \mathrm{~V} / \mathrm{V})$ and acetone, which was performed for surface modification. The slurry and powder of LDH were used directly to prepare the LDH/PP composites. In a similar procedure, $\mathrm{Zn}_{2} \mathrm{Al}-\mathrm{H}_{2} \mathrm{D}_{1}-\mathrm{LDH}, \mathrm{Zn_{2 }} \mathrm{Al}-\mathrm{H}_{1} \mathrm{D}_{2}-\mathrm{LDH}, \mathrm{Zn_{2 }} \mathrm{Al}-\mathrm{HALS}-\mathrm{LDH}$ and $\mathrm{Zn}_{2} \mathrm{Al}$-DBHP-LDH were also synthesized.

\subsection{Preparation of LDH/PP composites.}

LDH/PP composites were prepared by two methods: solvent mixing and extrusion mixing. ${ }^{30,31}$ The weight percentage of LDH in PP was confirmed as $4.0 \mathrm{wt} \%$. In the solvent mixing method, for example, $20.00 \mathrm{~g}$ PP and the fixed amount of LDH slurry (according to solid content) were dispersed in $70 \mathrm{~mL}$ xylene, then transferred to a round-bottomed glass reactor ( $500 \mathrm{~mL}$ capacity). Under vigorous stirring, the system was heated (up to $140{ }^{\circ} \mathrm{C}$ ) in a water cooled condenser. After 3 hours, the mixture was poured into $50 \mathrm{~mL}$ hexane immediately and cooled down to room temperature. The product was placed in a fume hood and finally dried. In the extrusion mixing method, for instance, $5.00 \mathrm{~g}$ PP and the corresponding LDH power were mixed and melt-processed in a twin screwed extruder equipment Haake Minilab Micro Compounder (at $180{ }^{\circ} \mathrm{C}, 100 \mathrm{rpm}$ for $5 \mathrm{~min}$ ). For comparison, the composites with physical mixing LDH fillers (HALS-LDH) $)_{x}(D B H P-L D H)_{y} / P P(x: y=1: 1,2: 1,1: 2)$ were carried out, as well as without any additive (PP) defined as reference composite. For further analysis, LDH/PP composites were pressed into polymer films (thickness of $\sim 0.1 \mathrm{~mm}$ ) between Teflon sheets at $170{ }^{\circ} \mathrm{C}$. Finally, PP composites using LDH filler in 4.0 wt\% loading HALS-LDH/PP, DBHP-LDH/PP, $\mathrm{H}_{1} \mathrm{D}_{1}$-LDH/PP, $\mathrm{H}_{2} \mathrm{D}_{1}$-LDH/PP, $\mathrm{H}_{1} \mathrm{D}_{2}$-LDH/PP, (H-LDH) $)_{1}(\mathrm{D}-$ $\mathrm{LDH})_{1} / \mathrm{PP},(\mathrm{H}-\mathrm{LDH})_{2}(\mathrm{D}-\mathrm{LDH})_{1} / \mathrm{PP},(\mathrm{H}-\mathrm{LDH})_{1}(\mathrm{D}-\mathrm{LDH})_{2} / \mathrm{PP}, \mathrm{HALS} / \mathrm{PP}$ and DBHP/PP films were individually prepared by the two described methods.

\subsection{Characterization.}

XRD measurements of LDH and LDH/PP composites were recorded on a powder X-ray diffractometer (Philipps X-Pert Pro) using Cu K $\alpha$ source $\left(\lambda=0.154 \mathrm{~nm}\right.$ ) from 2.0 to $70.0 / 2 \theta$ with a step size of $0.03^{\circ}$ and a step counting time of $10 \mathrm{~s}$. Small Angle X-ray Scattering (SAXS) experiments were performed on a Empyrean Panalytical equipment with a ScatterX78 using a $\theta / \theta$ goniometer and $\mathrm{Cu}$ anode $(45 \mathrm{kV}$ and $40 \mathrm{~mA})$. An elliptic W/Si focusing X-ray mirror for $\mathrm{Cu}$ radiation was used, and divergence fixed slit of $1 / 32^{\circ}$. The distance form incident beam to sample was 140 $\mathrm{mm}$. The detector GaliPIX3D was at a distance of $240 \mathrm{~mm}$ from the sample. SAXS curves were recorded in continuous scan mode. The background (no sample) was removed in each case. Fourier transform infrared (FT-IR) spectra were collected on a Thermo Scientific Nicolet 6700 FT-IR spectrometer using thin KBr pellets in the range of $4000-400 \mathrm{~cm}^{-1}$ in transmission mode. Thermogravimetric analysis (TGA) curves were examined by Perkin Elmer TGA4000 apparatus in air atmosphere (gas flow $30 \mathrm{~mL} / \mathrm{min}$ ) in the range of $30-700{ }^{\circ} \mathrm{C}$ with a heating rate of 10 ${ }^{\circ} \mathrm{C} / \mathrm{min}$. Solid state ${ }^{13} \mathrm{C} N \mathrm{NMR}(\mathrm{I}=1 / 2)$ experiments were carried out on a 300 Bruker spectrometer at $75.47 \mathrm{MHz}$, using magic angle spinning (MAS) condition at $10 \mathrm{kHz}$ and a $4 \mathrm{~mm}$ diameter size zirconia rotor. ${ }^{13} \mathrm{C}$ spectra obtained by proton enhanced cross-polarization method (CP) were referenced to the carbonyl of the glycine calibrated at $176.03 \mathrm{ppm}$. The rheological properties of LDH/PP composites were recorded up at $180{ }^{\circ} \mathrm{C}$ by a rotational spectrometer (ARES, TA, USA), with a parallel plate geometry using $8 \mathrm{~mm}$ diameter and a gap distance of $1 \mathrm{~mm}$. All the measurements were certainly within the linear viscoelastic region. The dynamic stress against oscillatory shearing frequency was from 0.1 to $100 \mathrm{rad} \mathrm{s}^{-1}$. As a function of the frequencies, $\mathrm{G}^{\prime}$ (storage modulus), $\mathrm{G}^{\prime \prime}$ (loss modulus) and ratio of $\mathrm{G}^{\prime \prime}$ on $\mathrm{G}^{\prime}(\tan \delta)$ were monitored automatically. Then, the Cole-Cole plot curves containing storage viscosity $\left(\eta^{\prime}=G^{\prime \prime} / \omega\right)$ and loss viscosity $\left(\eta^{\prime \prime}=G^{\prime} / \omega\right)$ were preferred for discussion. Newtonian zero-shear viscosity $\eta_{0}^{\prime}$ of PP was obtained by extrapolating the semi-circular depression in consistent with $\eta_{0}^{\prime}=\mathrm{K}$ $\mathrm{M}_{\mathrm{w}}{ }^{\mathrm{a}}$.

\subsection{Thermal properties of LDH/PP composites.}


The thermal properties of LDH/PP composites were analyzed by two methods: thermalgravimetric analysis (TGA) and accelerated thermal-aging. The LDH/PP composites with different mass loadings in terms of LDH nanofiller were analyzed with a heating condition at $10{ }^{\circ} \mathrm{C} / \mathrm{min}$ from $25^{\circ} \mathrm{C}$ to $600{ }^{\circ} \mathrm{C}$. Thermal-aging experiments on LDH/PP composites were conducted with a constant temperature at $150{ }^{\circ} \mathrm{C}$, and the thermal aging behavior of $\mathrm{LDH} / \mathrm{PP}$ composites was recorded by the FT-IR spectra every $80 \mathrm{~min}$. As the aging time increased, the increasing area of IR absorption band $\left(1810-1660 \mathrm{~cm}^{-1}\right)$ was used to evaluate the thermal-aging degree. ${ }^{32}$

\subsection{Light-aging test of LDH/PP composites}

Light-aging test of LDHs/PP composites was carried out in a UV-accelerated light-aging equipment with a UV lamp $\left(1000 \mathrm{~W}, \lambda_{\max }=365 \mathrm{~nm}\right)$, and the corresponding FT-IR spectra were also recorded to evaluate the light-aging process every $10 \mathrm{~min}$.

\section{Results and discussion}

\subsection{Structural analysis of $\mathrm{Zn}_{2} \mathrm{Al}-\mathrm{LDH}$ nanofillers}

Fig. 1 shows the XRD patterns of the five $Z \mathrm{n}_{2} \mathrm{Al}$-LDH samples, and Table S1 (See Supporting Information) lists the associated crystallographic data and chemical compositions. In each case, the characteristic Bragg reflection peaks of $\mathrm{Zn}_{2} \mathrm{Al}-\mathrm{LDH}$ exhibit a series of basal reflections (00I) at low angles and the reflection (110) at higher angle, indicating that a layered structure and an intra-layer structural ordering are formed. ${ }^{33}$ The HALS-LDH and DBHP-LDH display diffraction reflections (003) at $7.5^{\circ}$ and $3.3^{\circ} / 2 \theta$, corresponding to the $d$-spacing distances of 1.17 and $2.63 \mathrm{~nm}$, respectively. The basal spacing of co-intercalated $\mathrm{H}_{\mathrm{x}} \mathrm{D}_{\mathrm{y}}-\mathrm{LDH}$ is almost the same with that of DBHP-LDH, because the DBHP anion is of larger size than HALS anion. Furthermore, compared with DBHP-LDH and $H_{x} D_{y}-L D H$, the corresponding Bragg peaks of HALS-LDH are significantly broader in terms of (00I), this in association with a diffraction intensity much lower, thus resulting in this case in a strong structural disorder in the LDH platelets stacking. The XRD patterns of the five $Z n_{2} A l-L D H$ samples show the absence of the carbonate phase $\left(\mathrm{Zn}_{2} \mathrm{Al}-\mathrm{CO}_{3}-\mathrm{LDH}\right.$ presents a basal spacing value of $\left.7.6 \AA\right)$, ${ }^{34}$ indicating that the amount of $\mathrm{Zn}_{2} \mathrm{Al}-\mathrm{CO}_{3}-\mathrm{LDH}$ impurity is lower than the detected limit of XRD equipment. That is to say, the co-precipitation method is available to prepare the intercalated LDH.

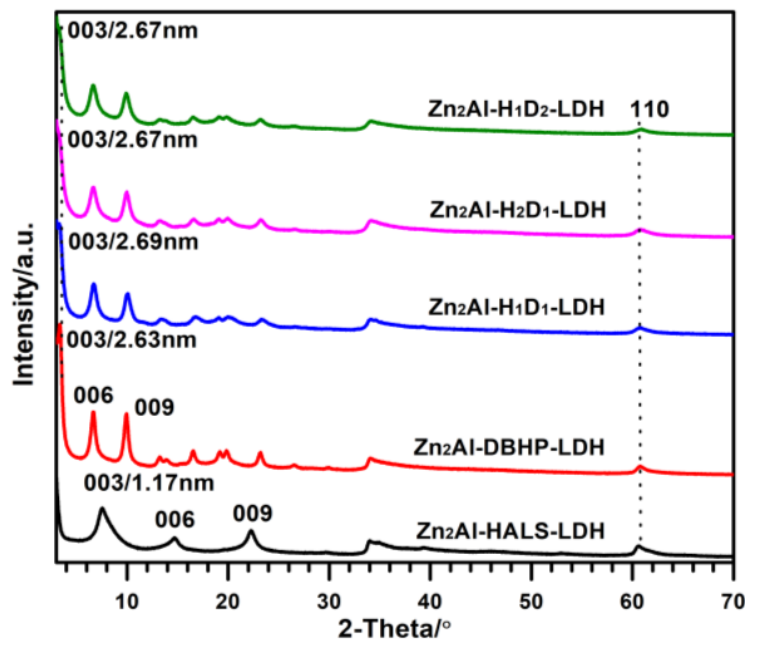

Fig. 1 XRD of $Z n_{2} A I-H A L S-L D H, Z n_{2} A I-D B H P-L D H$ and $Z n_{2} A I-H_{x} D_{y}-L D H(x: y=1: 1,2: 1,1: 2)$. 

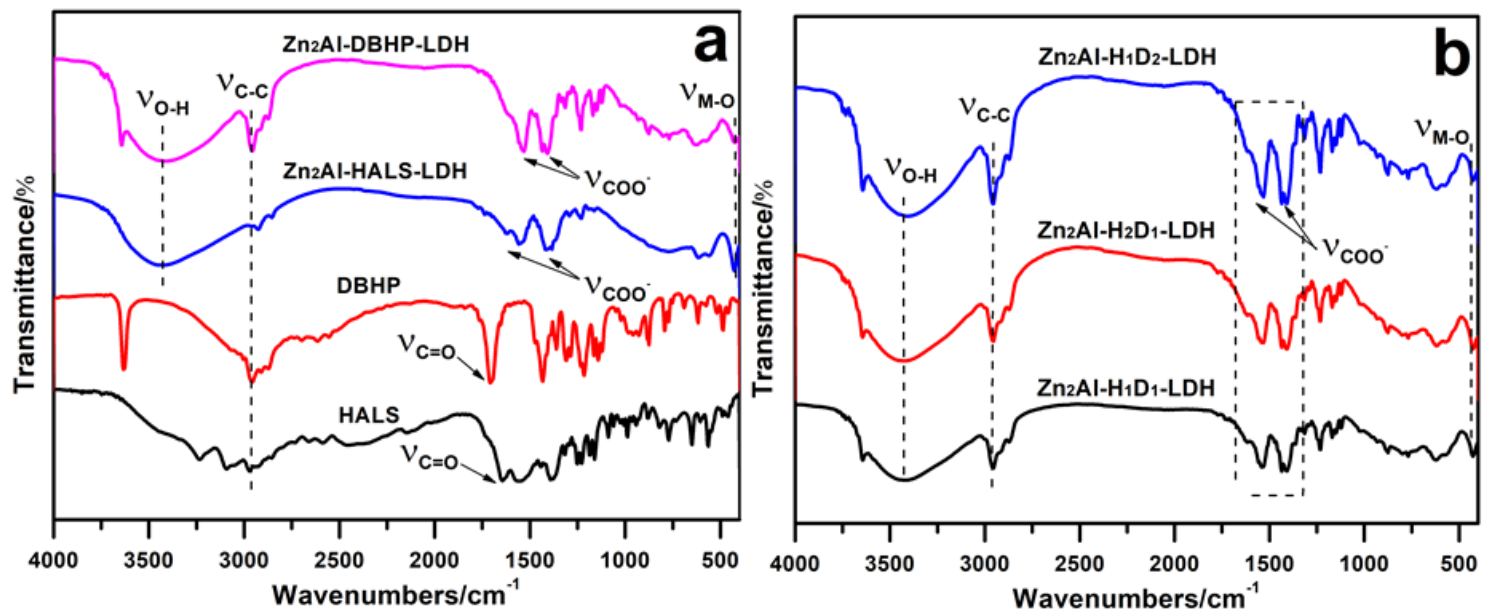

Fig. 2 FT-IR spectra of (a) HALS, DBHP, $Z n_{2} A I-H A L S-L D H$ and $Z n_{2} A I-D B H P-L D H$, (b) $Z n_{2} A I-H_{x} D_{y}-L D H$ ( $x: y=1: 1,2: 1$, $1: 2)$.

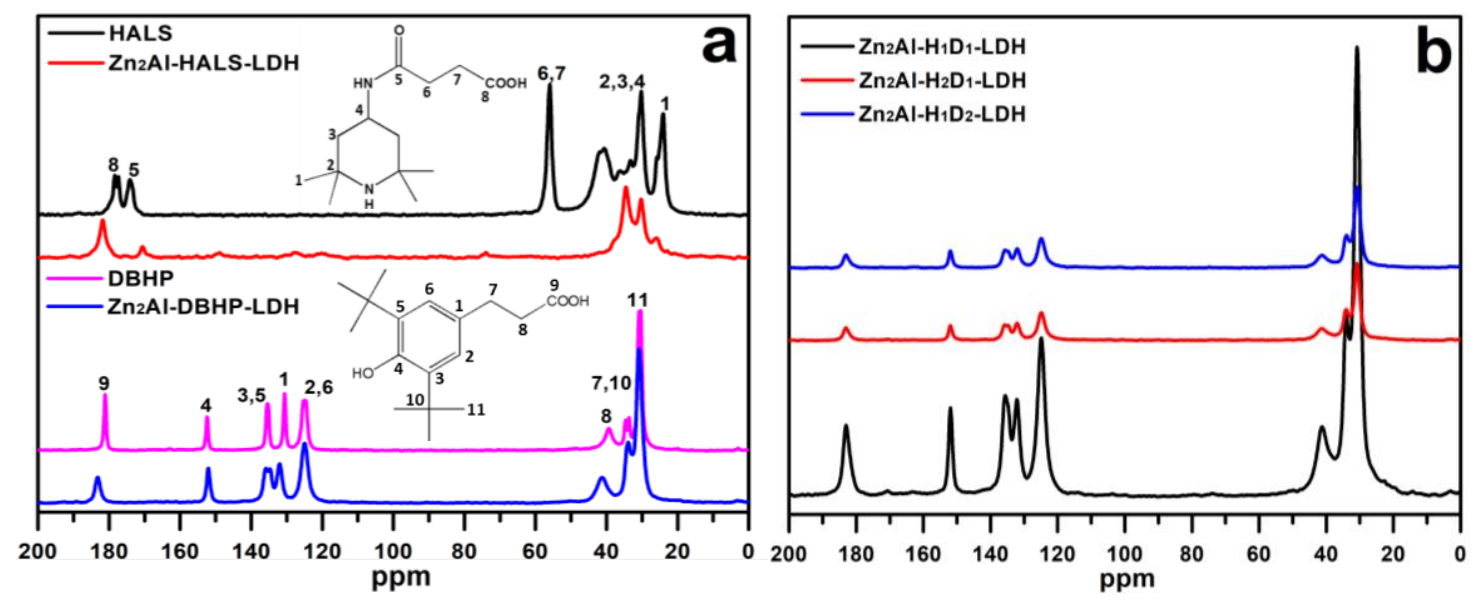

Fig. $3{ }^{13} \mathrm{C}$ NMR CPMAS spectrum of (a) HALS, Zn $\mathrm{n}_{2}$ Al-HALS-LDH and DBHP, $Z n_{2} A$ I-DBHP-LDH, (b) Zn ${ }_{2}$ Al-H $\mathrm{H}_{\mathrm{x}} \mathrm{D}_{\mathrm{y}}-\mathrm{LDH}(\mathrm{x}: \mathrm{y}=$ $1: 1,2: 1,1: 2)$.

The co-existence of HALS and DBHP anions in the vicinity of LDH platelets is further confirmed by the FT-IR spectra in Fig. 2, knowing that IR spectroscopy cannot address adsorption versus intercalation. All $\mathrm{Zn}_{2} \mathrm{Al}-\mathrm{LDH}$ samples show characteristic IR absorption bands of $\mathrm{Zn} \mathrm{n}_{2} \mathrm{Al}-\mathrm{LDH}$. Lattice vibration (M-O and O-M-O) appears at $427 \mathrm{~cm}^{-1}$, indicating the formation of $\mathrm{Zn}{ }_{2} \mathrm{Al}-\mathrm{LDH}$ platelet structure. The broad band around $3420 \mathrm{~cm}^{-1}$ is attributed to hydroxyl present in the brucite-like layer and the $\mathrm{O}-\mathrm{H}$ stretching vibration of water molecules. Simultaneously, the carbonyl stretching vibration coming from HALS and DBHP species are also observed. The position of vibration bands of $\mathrm{COO}^{-}$are shifted from 1644 and $1391 \mathrm{~cm}^{-1}$ to 1618 and 1415 $\mathrm{cm}^{-1}$ for HALS, 1707 and $1432 \mathrm{~cm}^{-1}$ to 1532 and $1408 \mathrm{~cm}^{-1}$ for DBHP. The splitting between asymmetrical and symmetrical mode $\Delta \mathrm{v}\left(\mathrm{COO}^{-}\right)=\mathrm{v}_{\mathrm{as}}-\mathrm{v}_{\mathrm{s}}$, is changed between the guest molecular and its intercalated LDH, which means the coordination mode between the functional group of the carboxylate ion and the metal laminate is modified. ${ }^{35}$ The coordination mode changed from monodentate character into bridging character (from $\Delta v=$ $253 \mathrm{~cm}^{-1}$ of HALS to $\Delta v=203 \mathrm{~cm}^{-1}$ of HALS-LDH) and monodentate character into a more chelating character (from $\Delta v=275 \mathrm{~cm}-1$ of DBHP to $\Delta v=124 \mathrm{~cm}-1$ of DBHP-LDH). Also, similar shifts in coordination model are also found in co-intercalated HxDy-LDH. That is to say that upon intercalation, there is a change of symmetry of the carboxylation functional group because HALS and DBHP interact electrostatically with the inner $\mathrm{OH}$-bearing LDH layers surface. In addition, no absorption bands of carbonate or nitrate anions is observed, neither CO3 $(1357 \mathrm{~cm}-1)$ nor $-\mathrm{NO} 3(1383 \mathrm{~cm}-1)$, indicating that the absence of these two contaminations. 
Solid state 13C NMR CPMAS spectra of HALS and DBHP before and after its incorporation between LDH layers are also compared (Fig. 3). Also, the peaks assignment of HALS and DBHP anion carbon nuclei is displayed in the figure. After the intercalation of HALS and DBHP molecules into LDH, some resonance peaks are shifted. Between HALS and HALS-LDH, large shifts in the resonance lines of HALS-LDH are observed for most of the carbon nuclei close to the carboxylate group, C8. Indeed, its value is deshielded when HALS molecule is interleaved. This is usually explained by the electrostatic interaction between carboxyl function and the LDH inner-surface, this effect propagates along the alkyl chain since $\mathrm{C} 6$ and $\mathrm{C} 7$ are both highfield shifted, as well as C5 to less extent as C5 is bearing a carbonyl function. The carbon nuclei from the piperidine cycle is found unmodified, this having in mind that $\mathrm{CP}$ sequence is not quantitative, the change in intensity is not discussed. Similar observation may be carried out between the spectrum of DBHP molecule and when interleaved: the carboxylate C9 is also down-field shifted while the carbon nuclei C7 and C8 next to C9 are shifted to higherfield. For the other carbon nuclei, their chemical shift is found unchanged, this arising from the butylphenol cycle averaging the interaction and by the fact that the ter-butyl groups are too far from the tethering carboxylate group. Altogether, one notes that the down-field shift on the carboxylate is larger for HALS than for DBHP, and so the high-field shifts of both carbon nuclei of the alkyl chain next to carboxylate. This may be interpreted by an electrostatic interaction more efficient for HALS than for DBHP, this tentatively explains here by the more cumbersome molecule DBHP (larger basal spacing) but also strongly hydrophobic with the presence of ter-butyl compared with tetra-methyl for HALS. The net difference in electrostatic interaction between the organic anions and the host sheets $\mathrm{Zn}_{2} \mathrm{Al} L \mathrm{LH}$ was also confirmed by FT-IR spectra, as well as between both interleaved families with $\Delta v\left(\mathrm{COO}^{\circ}\right)=203$ and $124 \mathrm{~cm}^{-1}$ for HALS- and DBHP-LDH, respectively (vide supra). Similar changes are also depicted in the series of co-intercalated $\mathrm{H}_{x} \mathrm{D}_{\mathrm{y}}-\mathrm{LDH}$ samples.
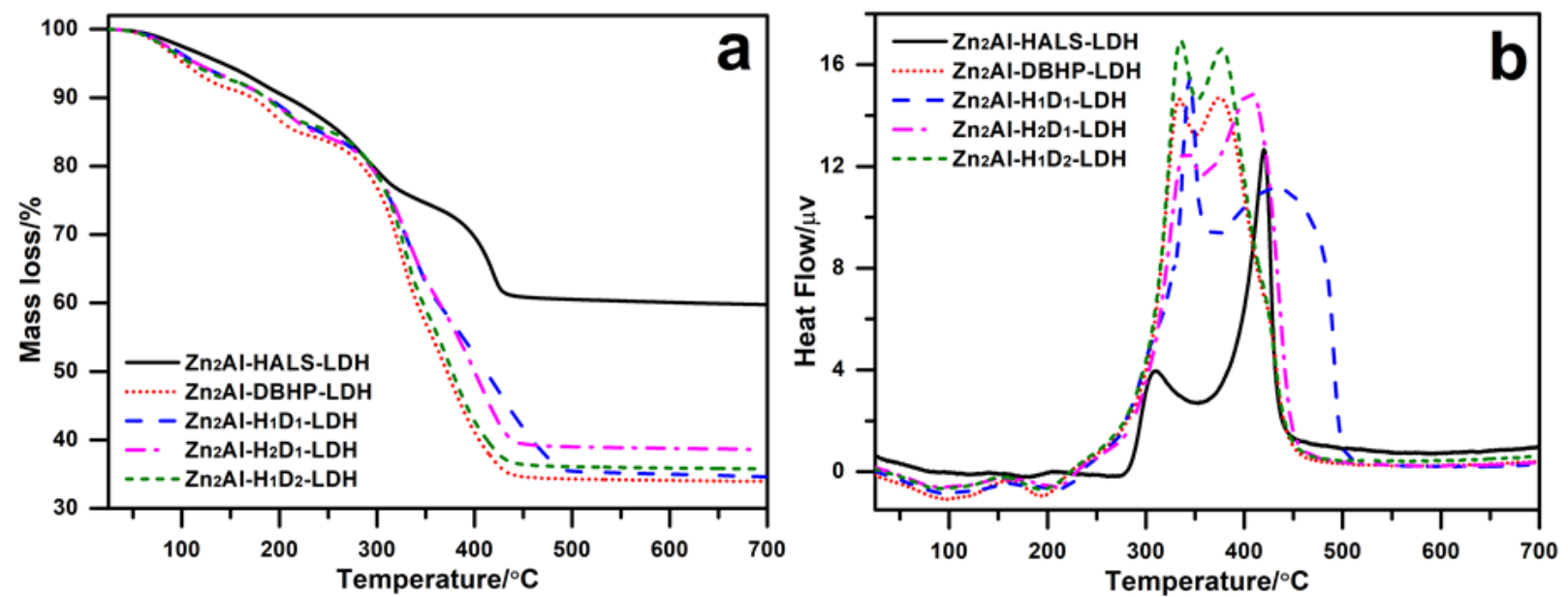

Fig. 4 (a) TG and (b) DTA curves of $Z n_{2} A I-H A L S-L D H, ~ Z n_{2} A I-D B H P-L D H$ and $Z n_{2} A I-H_{x} D_{y}-L D H ~(x: y=1: 1,2: 1,1: 2$ ).

Besides, the thermal behavior has been assessed by thermogravimetry. Fig. 4 depicts the thermogravimetric curves of $\mathrm{Zn}_{2} \mathrm{Al}-\mathrm{LDHs}$ and Table S2 (See Supporting Information) lists the corresponding data. The TG curves of HALS and DBHP show a single mass loss step $\left(200-350{ }^{\circ} \mathrm{C}\right)$, corresponding to the DTA exothermic peak at 300 and $306^{\circ} \mathrm{C}$, due to the decomposition of HALS and DBHP molecules. ${ }^{28,29}$ The thermal decomposition of LDHs occurs in different steps: (1) the removal of absorbed and interlayer water molecules (before $220^{\circ} \mathrm{C}$ ); (2) the loss of metal hydroxide layer (220$\left.360^{\circ} \mathrm{C}\right)$; (3) the decomposition of interlayer organic anion $\left(330-500^{\circ} \mathrm{C}\right)$. A partially overlap between the second and third mass loss is commonly observed. From the total weight loss, one can estimate the organic content that results in the chemical formulae of the $\mathrm{Zn}_{2} \mathrm{Al}-\mathrm{LDH}$ s reported in Table S1 (See Supporting Information). The residual mass at $700{ }^{\circ} \mathrm{C}$ is considered as " $\mathrm{Zn}_{2} \mathrm{AlO}_{7 / 2}$ ", which is related to the molecular weight at ambient temperature by the loss percentage. ${ }^{36}$ According to the feed conditions, all guest molecules appear to be present in a ratio of $1 / 1$ relative to $\mathrm{Al}^{3+}$. The thermal 
stability is also expressed by DTA and the temperatures at the mass loss of a determined amount (e.g., $50 \%$, at $\mathrm{T}_{50}$ ). LDHs have high $\mathrm{T}_{50}$, within the range from $371{ }^{\circ} \mathrm{C}$ (for DBHP-LDH) up to $411^{\circ} \mathrm{C}$ (for $\left.\mathrm{H}_{1} \mathrm{D}_{1}-\mathrm{LDH}\right)$, and the DTA exothermic peak of $\mathrm{H}_{1} \mathrm{D}_{1}-\mathrm{LDH}$ at 344 and $435^{\circ} \mathrm{C}$. After intercalated into the LDH layers, the decomposition temperature of HALS and DBHP molecular is increased, and the series of co-intercalated $H_{x} D_{y}-L D H$ exhibit higher thermal stability than HALS(DBHP)-LDH, especially $H_{1} D_{1}$ $\mathrm{LDH}$. All these results suggest that the intercalated structure LDH significantly improves the thermal stability of guest species due to the interaction between the guest species and the LDH host sheet. Certainly, the interaction favorably inhibits the migration of guest species from the intercalated LDH.

\subsection{Structure analysis of LDH/PP composites}

Fig. 5a and $\mathrm{b}$ demonstrate XRD patterns of the LDH/PP composite films by the solvent mixing method following the hot-pressed process. PP free of LDHs presents a XRD silent in the low $2 \theta$ angular domain $\left(2-10^{\circ}\right)$. When the hybrid $L D H$ materials are dispersed into PP, the corresponding XRD for DBHP-LDH/PP and HXDy-LDH/PP show some characteristic 00l reflections. Compared with LDH pristine samples, the positions are slightly shifted to lower $2 \theta$ angles corresponding to a change in the basal distance from $2.69 \mathrm{~nm}$ (Fig. 1) to $2.95 \mathrm{~nm}$ (Fig. 5a), thus indicating that some polymer chains are possibly diffusing within LDH gap.37 However, for the HALS-LDH/PP and (H-LDH)x(D$\mathrm{LDH}) \mathrm{y} / \mathrm{PP}$ composites, one note the quasi-absence of $(00 \mathrm{l})$ peaks of $\mathrm{LDHs}$, this time informing that the layers of LDHs initially stacked are extensively dispersed and even exfoliated into the PP matrix. At larger angular domain, $\mathrm{X}$-ray patterns exhibit the characteristic Bragg reflections assigned to (110), (040), (130), (111) and (131)/(041) planes of ?-form PP crystal. The diffraction peak positions are modifying neither by their position nor their FWHM intensity, thus indicating that the incorporation of LDHs does not affect the crystallized domains of PP. Fig. $5 c$ shows the IR spectra of LDH/PP composites. All the samples demonstrate the methyl and methylene characteristic bands of PP, e.g. 2950, 2915, 2868, 2837, 1454, and $1375 \mathrm{~cm}-1$. Similar situations have also been found in PP composites prepared by extrusion mixing, see Supporting Information Fig. S1. As the result, the addition of LDHs is found to lead well dispersed platelets into PP, and their effect on the molecular vibrational motions and overall structure of PP was negligible. 

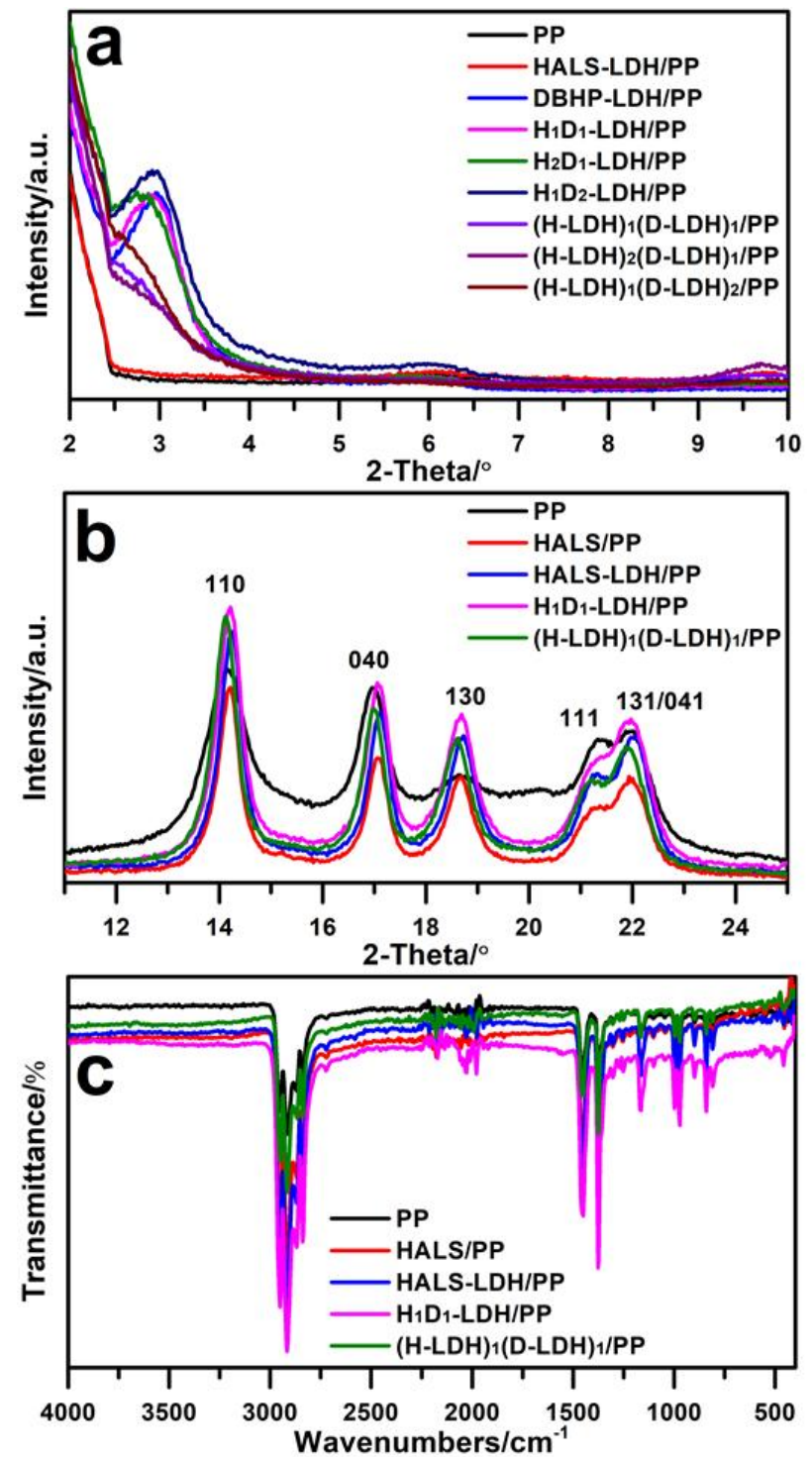

Fig. 5 XRD patterns of LDH/PP composites in (a) $2-10^{\circ}$, (b) $11-25^{\circ} / 2 \theta$ and (c) FT-IR spectra of LDH/PP composites prepared by solvent mixing method. 


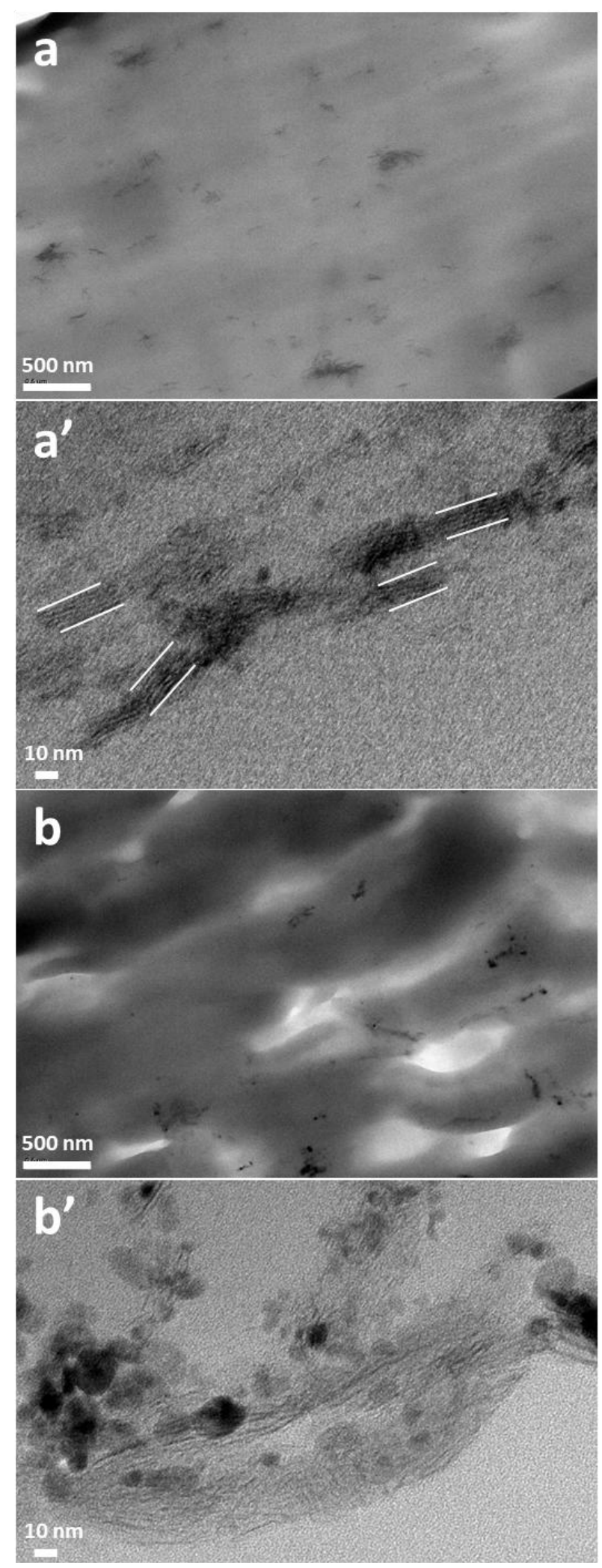

Fig. 6 TEM images of the $\mathrm{H}_{1} \mathrm{D}_{1}-\mathrm{LDH} / \mathrm{PP}\left(\mathrm{a}\right.$ and $\left.\mathrm{a}^{\prime}\right)$ and $(\mathrm{H}-\mathrm{LDH})_{1}(\mathrm{D}-\mathrm{LDH})_{1} / \mathrm{PP}\left(\mathrm{b}\right.$ and $\left.\mathrm{b}^{\prime}\right)$ prepared by solvent mixing method. Insets present the enlarged region for clear observation.

Besides, Fig. 6 displays the TEM images of $\mathrm{H}_{1} \mathrm{D}_{1}$-LDH/PP and $(\mathrm{H}-\mathrm{LDH})_{1}(\mathrm{D}-\mathrm{LDH})_{1} / \mathrm{PP}$ composites prepared by the solvent mixing method. At low magnification images $(a, b)$, some speckles are randomly distributed in PP, suggesting that the LDH fillers are evenly dispersed in PP. At high magnification images $\left(a^{\prime}, b^{\prime}\right)$, the edges of LDH fillers appear rather blurry, indicating an intimate 
mixing between the both components, most probably arising from the chemical modification by organic solvent that improves the compatibility of LDH in PP. It is worth noting that the distinct layer structure from $L D H$ can be observed in $\mathrm{H}_{1} \mathrm{D}_{1}-\mathrm{LDH} / \mathrm{PP}$, with the basal distance of $\sim 3 \mathrm{~nm}$. $\mathrm{H}_{1} \mathrm{D}_{1}-\mathrm{LDH}$ show a certain degree of incomplete exfoliation in PP. However, this situation is not observed in $(\mathrm{H}-$ $\mathrm{LDH})_{1}(\mathrm{D}-\mathrm{LDH})_{1} / \mathrm{PP}$, where small aggregates are depicted only. In both cases, it is consistent with the $\mathrm{XRD}$ analysis results at low $2 \theta$ values.

To further unravel the structural arrangement of the fillers into PP, SAXS is conducted and the corresponding results are described in Fig. 7. For the series using the solvent mixing, most of the samples present a hump located at a diffusion values q of $0.033 \AA^{-1}$, corresponding to a distance of $3.0 \mathrm{~nm}$. For HALS-LDH and the physical mixture, such hump is absent, underling a degree of exfoliation, as already observed on the wide-angle XRD analysis. When decreasing $q$, the slope is constant showing that there is no other particle size in the scanned domain (up to $100 \mathrm{~nm}$ ). At $\mathrm{q}<$ $0.07 \AA^{-1}$, the good linear fit of HALS-LDH/PP and $(H-L D H)_{x}(D-L D H)_{y} / P P$ confirms full exfoliation of LDH clay platelets. The slope of -2 for $(\mathrm{H}-\mathrm{LDH})_{1}(\mathrm{D}-\mathrm{LDH})_{1} / \mathrm{PP},(\mathrm{H}-\mathrm{LDH})_{1}(\mathrm{D}-\mathrm{LDH})_{2} / \mathrm{PP}$ and -2.2 for HALS$\mathrm{LDH} / \mathrm{PP}, \quad(\mathrm{H}-\mathrm{LDH})_{2}(\mathrm{D}-\mathrm{LDH})_{1} / \mathrm{PP}$ are consistent with scattering from isolated two-dimensional platelets. ${ }^{38}$ For the series of extrusion-made samples, the characteristic hump at around $q=0.03 \AA^{-1}$ is visible with pronounced shifts in some cases. Only, HALS-LDH does not present such hump. Additional changes of slope are indicative of correlative distances. For instance, it is observed at $q=$ $0.0065 \AA^{-1}$ for $\mathrm{H}_{2} \mathrm{D}_{1}-\mathrm{LDH}$, that corresponds to a distance of $15.4 \mathrm{~nm}$. Below this value (in q), the slope is more horizontal, indicative that there is no more aggregation/correlation at larger distance scale. ${ }^{39}$
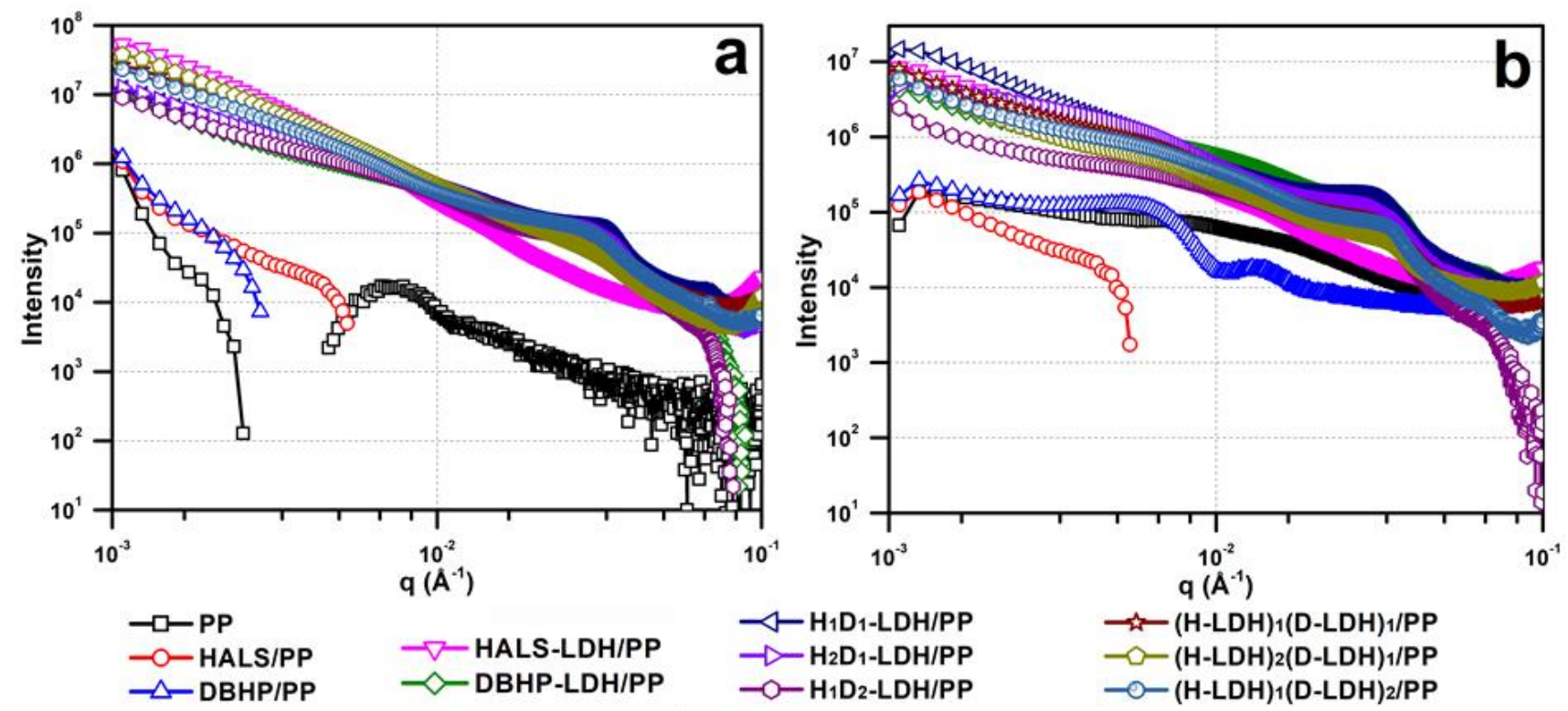

Fig. 7 SAXS data for PP composites prepared by (a) solvent mixing method and (b) extrusion mixing method.

To further investigate the microstructural changes of PP composites, rheology analysis in PP molten state was scrutinized. The rheological properties of composites are affected by many factors, such as dispersion state, nano-structure and the interaction at the interface here between filler platelets and polymer chains. The rheological data in Cole-Cole representation, $\eta^{\prime \prime}-\eta^{\prime}(\omega)$, are chosen to express viscoelastic behavior, because any change in the molecular weight $\left(M_{w}\right)$ and molecular weight distribution (MWD) is directly evidenced on the viscoelastic behavior $\eta^{\prime \prime}-\eta^{\prime}(\omega) .^{40}$ From the Cole-Cole plots of LDH/PP composites (Fig. 8a and Fig. 8b), a depressed semi-circle associated to a Newtonian behavior is observed. The convex downward semi-circular profile at the intercept $\eta^{\prime \prime}$ tending to 0 corresponds to the Newtonian zero-shear viscosity $\eta_{0}^{\prime}$ when $\omega$ tends to 0 , and related to the 
apparent $\mathrm{M}_{\mathrm{w}}$ by the empirical relationship $\eta_{0}^{\prime}=\mathrm{K} \cdot \mathrm{M}_{\mathrm{w}}{ }^{3.4}$, where $\mathrm{K}=4.7 \times 10^{-9}$. When $\mathrm{LDH}$ nanofillers are incorporated into a PP matrix, the Newtonian zero-shear viscosity of LDH/PP composites is shifted to higher value. That can be interpreted as a chain extender effect of the LDH/PP composites and related to an efficient interfacial interaction between LDH and PP chains. LDH fillers play a reinforcing role toward PP and appear to be tunable as the function of the nature of the organic molecule tethered to the inorganic platelets.
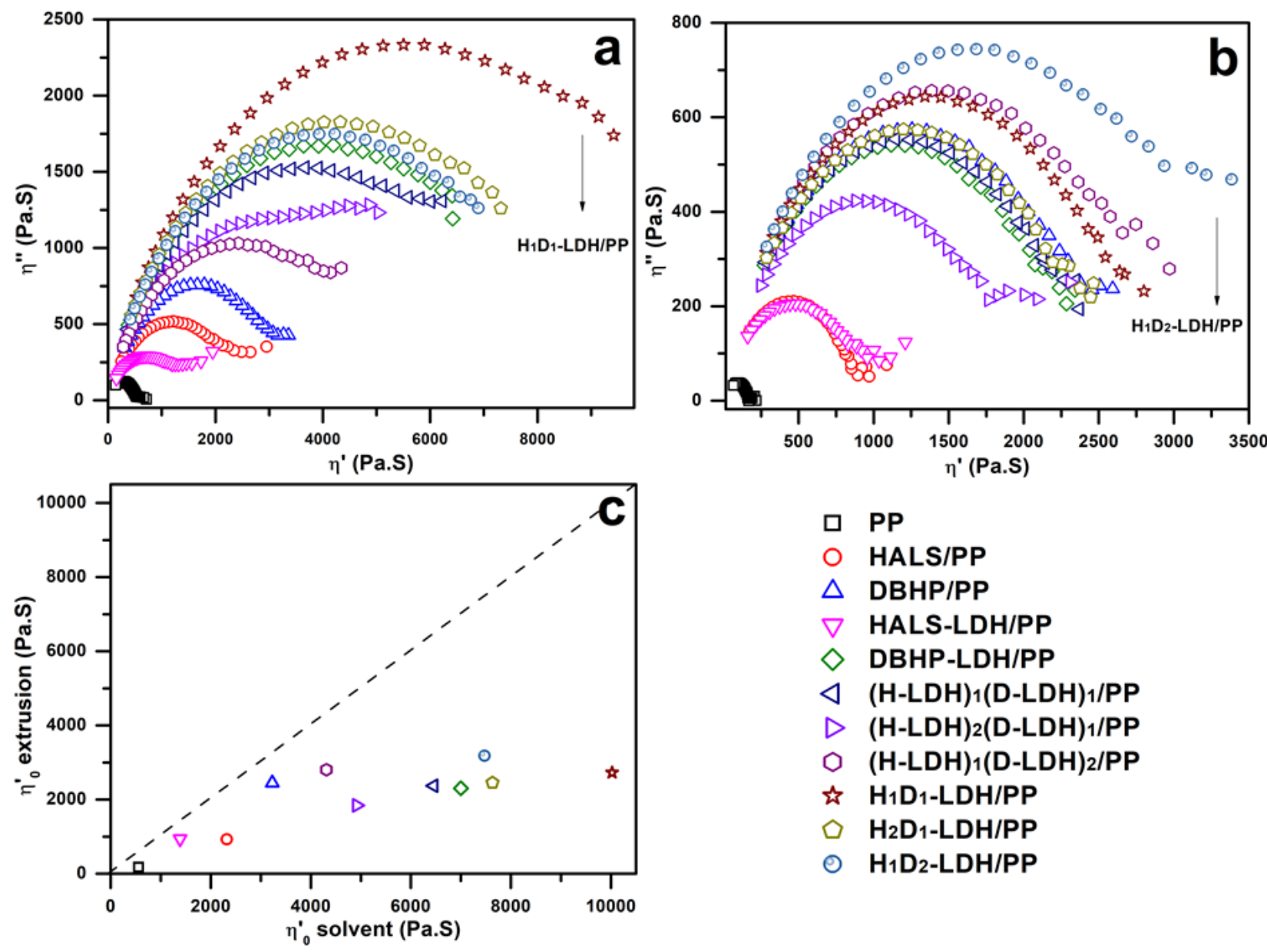

Fig.8 Cole-Cole plots of PP composites prepared by (a) solvent mixing method and (b) extrusion mixing method. (c) Correlation between both dispersion processes.

$\mathrm{LDH} / \mathrm{PP}$ composites prepared by the solvent mixing method, the values of viscosity range in the order: $\mathrm{PP}<$ HALS-LDH/PP $<$ HALS/PP $<$ DBHP/PP $<(H-L D H)_{1}(\mathrm{D}-\mathrm{LDH})_{2} / \mathrm{PP}<(\mathrm{H}-\mathrm{LDH})_{2}(\mathrm{D}-\mathrm{LDH})_{1} / \mathrm{PP}<(\mathrm{H}-\mathrm{LDH})_{1}(\mathrm{D}-\mathrm{LDH})_{1} / \mathrm{PP}<\mathrm{DBHP}-$ LDH/PP $<\mathrm{H}_{1} \mathrm{D}_{2}-\mathrm{LDH} / \mathrm{PP}<\mathrm{H}_{2} \mathrm{D}_{1}-\mathrm{LDH} / \mathrm{PP}<\mathrm{H}_{1} \mathrm{D}_{1}-\mathrm{LDH} / \mathrm{PP}$. LDH/PP composites prepared by extrusion mixing present a much lower viscosity compared with solvent mixing composites, with the viscosities ranging in the order: $\mathrm{PP}<$ HALS/PP $<$ HALS-LDH/PP $<(H-L D H)_{2}(D-L D H)_{1} /$ PP $<$ DBHP-LDH/PP $<(H-L D H)_{1}(D-L D H)_{1} / P P<$ DBHP $/$ PP $<H_{2} D_{1}-L D H / P P$ $<\mathrm{H}_{1} \mathrm{D}_{1}-\mathrm{LDH} / \mathrm{PP}<(\mathrm{H}-\mathrm{LDH})_{1}(\mathrm{D}-\mathrm{LDH})_{2} / \mathrm{PP}<\mathrm{H}_{1} \mathrm{D}_{2}-\mathrm{LDH} / \mathrm{PP}$. The auto-correlation curve of $\eta_{0}^{\prime}$ between both mixing methods is shown in Fig. 8c. Indeed comparing both methods of dispersion, $\eta_{0}^{\prime}$ values of the solvent mixing composites are found to be much larger than that of the extrusion mixing composites, indicating that there is no linear relationship between the two mixing methods. Therefore, co-intercalated $H_{x} D_{y}-L D H$ fillers provoke a strong chain extension effect on PP, even more pronounced for $\mathrm{H}_{1} \mathrm{D}_{1}$ co-added guest molecules. At the same 4 wt\% loading, the solvent mixing LDH/PP composites seem to perform better than extrusion mixing LDH/PP ones. These results suggest an efficient dispersion of $\mathrm{LDH}$ in PP with interfacial interaction largely developed through solvent mixing and an improvement in mechanical properties for the polymer materials.

\subsection{Thermal properties of LDH/PP composites.}


In the following, the series of composites prepared by the solvent mixing method will be considered only. Fig. 9a reports the thermogravimetric analysis (TGA) of the LDH/PP composites and Table S3 (See Supporting Information) lists the data concerning the decomposition temperatures. The main mass loss process for all the samples takes place in the range of $250-400{ }^{\circ} \mathrm{C}$. The degradation process at $\mathrm{T}_{\text {onset }}$ for LDH/PP located at higher temperatures than that of PP, which indicated that the incorporation of LDH improves the thermal stability of the composites. The temperature at which the composites lose a determined amount of weight $\left(50 \%, T_{50}\right)$ are considered here for comparison, $T_{50}$ ranges as: $\mathrm{H}_{x} \mathrm{D}_{y}-\mathrm{LDH} / \mathrm{PP}>(\mathrm{H}-\mathrm{LDH})_{\mathrm{x}}(\mathrm{D}-\mathrm{LDH})_{\mathrm{y}} / \mathrm{PP}>\mathrm{HALS}(\mathrm{DBHP})-\mathrm{LDH} / \mathrm{PP}>\mathrm{HALS}(\mathrm{DBHP}) / \mathrm{PP}>\mathrm{PP}$. In all the cases, $T_{50}$ gradually increases from 331 (for PP) up to $399^{\circ} \mathrm{C}$ (for $\mathrm{H}_{1} \mathrm{D}_{1}-\mathrm{LDH}$ ). For the latter $\mathrm{H}_{1} \mathrm{D}_{1}$ $\mathrm{LDH}$ filler, $\mathrm{T}_{\text {onset }}$ is of $376^{\circ} \mathrm{C}$, also higher than the other fillers. Compared with single molecule (H or D) intercalated LDH filler or physically mixed LDH filler, the series of co-intercalated HxDy-LDH fillers endow PP with a remarkable improvement in the thermal stability, most probably arising from strong interfacial interaction as already underlined by rheology.
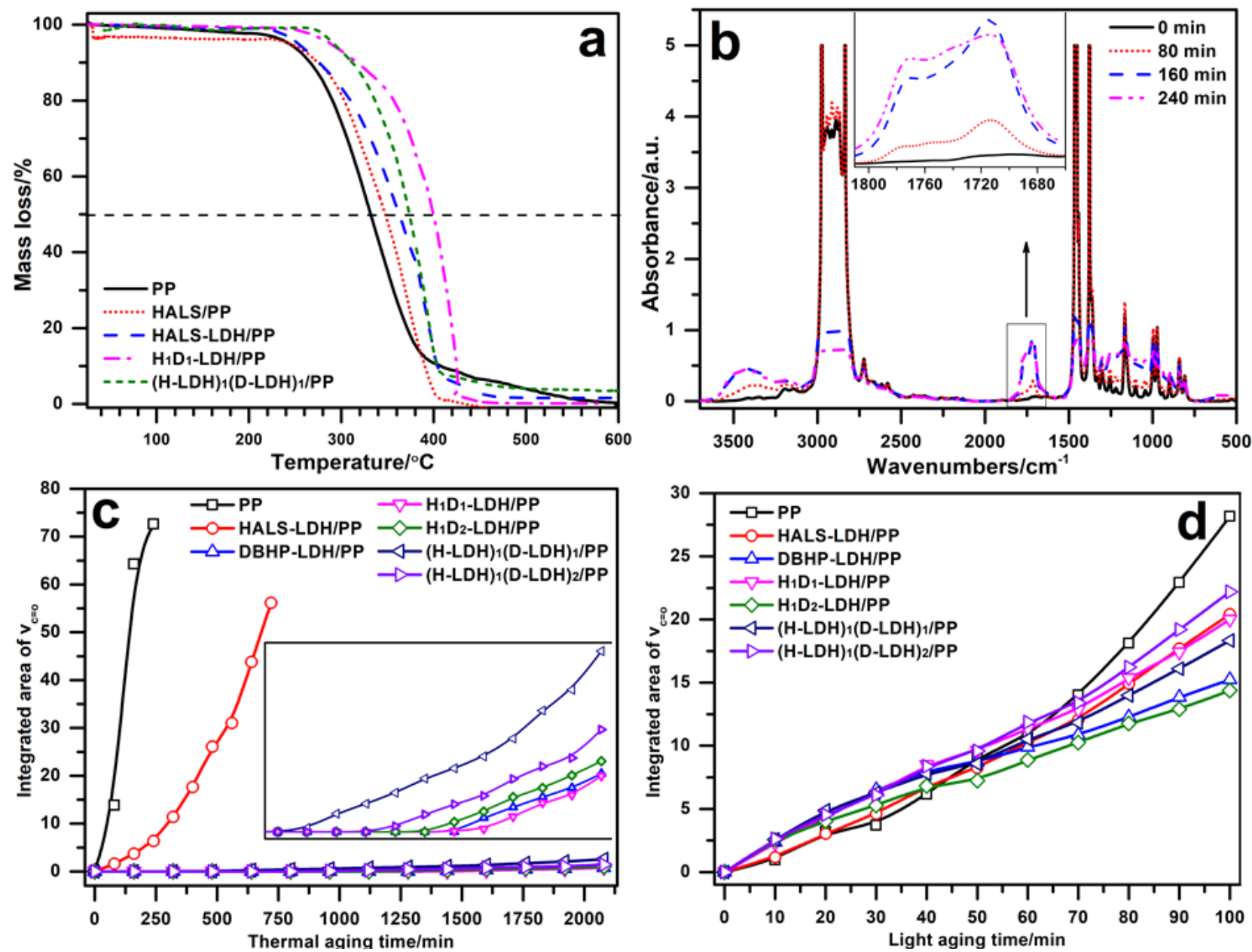

Fig. 9 (a) TGA curves of LDH/PP composites. (b) FT-IR spectra of pure PP during thermal aging. Carbonyl peak area of LDH/PP composites during (c) thermal aging and (d) light aging.

Another evaluation of thermal stability is to perform accelerated thermal aging. LDH/PP films were employed at $150{ }^{\circ} \mathrm{C}$ and tested with FT-IR every $80 \mathrm{~min}$. For example, Fig. 9b shows the FT-IR spectra of PP film (without LDH filler) at different aging times. The PP film gradually discolored, hardened and finally completely cracked within 240 minutes, this associated with the carbonyl absorption band $\left(1810-1660 \mathrm{~cm}^{-1}\right)$ becoming larger and larger. Therefore, the area of carbonyl absorption band can be used to evaluate the thermal aging degradation behavior of PP. Fig. 9c further depicts the integrated area of some LDH/PP composites after different aging times. There are three time-scales observed during the thermal-oxidative degradation: (1) a very short period during which PP film is totally broken after the thermal aging time of $240 \mathrm{~min}$, that shows that PP has no ability against thermal aging; (2) a medium period as HALS-LDH/PP that presents certain ability (about $720 \mathrm{~min}$ ) but not enough to be stabilized 
on a longer time, and (3) a much longer periods for other $\mathrm{LDH}$ fillers that show efficient effect on the long-term stability of LDH/PP composites and ranging as $\mathrm{H}_{1} \mathrm{D}_{1}$-LDH/PP $>$ DBHP-LDH/PP $>\mathrm{H}_{1} \mathrm{D}_{2}$-LDH/PP $>(\mathrm{H}-\mathrm{LDH})_{1}(\mathrm{D}-\mathrm{LDH})_{2} / \mathrm{PP}$ $>(\mathrm{H}-\mathrm{LDH})_{1}(\mathrm{D}-\mathrm{LDH})_{1} / \mathrm{PP}$. Thus, the series $\mathrm{H}_{\mathrm{x}} \mathrm{D}_{\mathrm{y}}-\mathrm{LDH}$ present much higher promoter action against the thermal aging of PP than that of HALS/DBHP-LDH and of the simple physical mixture $(H-L D H)_{x}(D-L D H)_{y}$. It underlines that the beneficial effect of the ratio between HALS and DBHP in the interlayer and their co-intercalated structure both retard the thermal-aging degradation for $\mathrm{PP}$, most presumably in a synergistic way.

\subsection{Light stability of LDH/PP composites.}

Furthermore, Fig. 9d displays the light-aging degradation of LDH/PP. In time, all the LDH/PP composites present a gradually increasing light oxidation following the aging time till $100 \mathrm{~min}$, and accordingly the carbonyl peak region is increased. The aging process is differentiated in two ways: (1) the integrated area of PP is slightly smaller than LDH/PP before $40 \mathrm{~min}$, underlining that LDH does not obviously succeed in inhibiting the lightoxidation degradation for PP at early exposure time. However, the difference of all samples is very small. (2) With the extension of aging time, PP exhibits the faster growth and larger intensity after $40 \mathrm{~min}$. It is indicated that LDH fillers have a positive effect on the long-term light-aging degradation of PP under the investigated conditions.

\section{Conclusions}

A preparation of HALS and DBHP co-intercalated into LDH to produce inorganic-organic hybrid co-intercalated material $\mathrm{Zn}_{2} \mathrm{Al}-\mathrm{H}_{\mathrm{x}} \mathrm{D}_{\mathrm{y}}-\mathrm{LDH}$, adjusting the guest anions ratio ( $\left.\mathrm{x}: \mathrm{y}=1: 1,2: 1,1: 2\right)$ was reported. LDH/PP nanocomposites based on HALS, DBHP and PP have been prepared by dispersing different LDH fillers in PP through two mixing methods: solvent mixing and extrusion mixing. The fillers are found to be well dispersed into polymers without influencing its crystallization state but providing a strong chain extension effect on PP, this even more pronounced for the series of co-intercalated $\mathrm{H}_{x} \mathrm{D}_{y}-\mathrm{LDH}$. Among the samples, the thermal stability of $\mathrm{H}_{x} \mathrm{D}_{\mathrm{y}}-\mathrm{LDH}$ composites is improved. Through the accelerated aging tests (thermal and UV exposure), the co-intercalated hybrid materials are found to decelerate the oxidative degradation for PP. The study underlines the beneficial and synergistic effect of using a co-intercalated $\mathrm{H}_{\mathrm{x}} \mathrm{D}_{\mathrm{y}}$-LDH hybrid structure as a new kind of toolbox, pushing even further the possibility of this host structure, with here tunable ratio for the co-added guest molecule for a better performance of PP in the selected applications.

\section{Conflicts of interest}

There are no conflicts to declare.

\section{Acknowledgements}

This work is supported by the National Natural Science Foundation of China, the Fundamental Research Funds for the Central Universities (JD1716, 12060093063), and Program for Changjiang Scholars and Innovative Research Team in University (No. IRT1205). The authors would like to thank CPER (challenge MMaSyF 2016) through the project METAPROFILE for the SAXS equipment.

\section{Notes and references}

1 S. D. Anuar Sharuddin, F. Abnisa, W. M. A. Wan Daud and M. K. Aroua, Energy Convers. Manage., 2016, 115, 308326.

2 T. V. Duncan, ACS Appl. Mater. Interfaces, 2015, 7, 20-39.

3 Y. Peng, R. Liu and J. Cao, Appl. Surf. Sci., 2015, 332, 253-259.

4 G. Zhang, C. Nam, T. C. M. Chung, L. Petersson and H. Hillborg, Macromolecules, 2017, 50, 7041-7051.

5 M. Norouzi, Y. Zare and P. Kiany, Polym. Rev., 2015, 55, 531-560.

6 M. Baron, J. C. Morris, S. Telitel, J. L. Clement, J. Lalevee, F. Morlet-Savary, A. Spangenberg, J.P. Malval, O. Soppera, D. Gigmes and Y. Guillaneuf, J. Am. Chem. Soc., 2018, 140, 3339-3344.

7 E. A. Haidasz, D. Meng, R. Amorati, A. Baschieri, K. U. Ingold, L. Valgimigli and D. A. Pratt, J. Am. Chem. Soc., 2016, 138, 5290-5298.

8 W. A. Yehye, N. A. Rahman, A. Ariffin, S. B. Abd Hamid, A. A. Alhadi, F. A. Kadir and M. Yaeghoobi, Eur. J. Med. Chem., 2015, 101, 295-312.

9 E. A. Haidasz, R. Shah and D. A. Pratt, J. Am. Chem. Soc., 2014, 136, 16643-16650.

10 J. Yang, Y. Huang, Y. Lv, S. Li, Q. Yang and G. Li, Carbon, 2015, 89, 340-349.

11 R. Li, K. Shi, L. Ye and G. Li, Compos. Part B-Eng., 2019, 162, 11-20.

12 Y. Yang, C. Hu, H. Zhong, X. Chen, R. Chen and K. L. Yam, J. Agr. Food Chem., 2016, 64, 7866-7873. 
13 K. A. Iyer, J. Lechanski and J. M. Torkelson, Compos. Part A-Appl. S., 2016, 83, 47-55.

14 J. Liu, H. Pu, S. Liu, J. Kan and C. Jin, Carbohydr. Polym., 2017, 174, 999-1017.

15 G. Zhang, C. Nam, L. Petersson, J. Jämbeck, H. Hillborg and T. C. M. Chung, Macromolecules, 2018, 51, $1927-1936$.

16 N. T. Dintcheva, R. Arrigo, E. Morici, C. Gambarotti, S. Carroccio, F. Cicogna and G. Filippone, Compos. Part B-Eng., 2015, 82, 196-204.

17 J. Bu, X. Huang, S. Li and P. Jiang, Carbon, 2016, 106, 218-227.

18 M. Kotal and A. K. Bhowmick, Prog. Polym. Sci., 2015, 51, 127-187.

19 D. Basu, A. Das, K. W. Stöckelhuber, U. Wagenknecht and G. Heinrich, Prog. Polym. Sci., 2014, 39, 594-626.

20 Q. Wang and D. O'Hare, Chem. Rev., 2012, 112, 4124-4155.

21 C. Li, M. Wei, D. G. Evans and X. Duan, Small, 2014, 10, 4469-4486.

22 H. Zhong, C. Campos-Roldán, Y. Zhao, S. Zhang, Y. Feng and N. Alonso-Vante, Catalysts, 2018, 8, 559.

23 X. Mei, W. Wang, L. Yan, T. Hu, R. Liang, D. Yan, M. Wei, D. G. Evans and X. Duan, Biomaterials, 2018, 165, 14-24.

24 E. N. Kalali, X. Wang and D. Wang, J. Mater. Chem. A, 2016, 4, 2147-2157.

25 D. Li, L. Qian, Y. Feng, P. Tang and L. Yang, ACS Appl. Mater. Interfaces, 2014, 6, 20603-20611.

26 Z. Gu, J. J. Atherton and Z. P. Xu, Chem. Commun., 2015, 51, 3024-3036.

27 C. Taviot-Guého, V. Prévot, C. Forano, G. Renaudin, C. Mousty and F. Leroux, Adv. Funct. Mater., 2017, 1703868.

28 Q. Zhang, F. Leroux, P. Tang, D. Li and Y. Feng, Polym. Degrad. Stab., 2018, 154, 55-61.

29 Q. Zhang, Q. Jiao, F. Leroux, P. Tang, D. Li and Y. Feng, New J. Chem., 2017, 41, 2364-2371.

30 Y. Gao, J. Wu, Z. Zhang, R. Jin, X. Zhang, X. Yan, A. Umar, Z. Guo and Q. Wang, J. Mater. Chem. A, 2013, 1, 99289934.

31 F. Leroux, A. Dalod, M. Hennous, L. Sisti, G. Totaro, A. Celli, C. Coehlo and V. Verney, Appl. Clay Sci., 2014, 100, 102-111.

32 Y. Feng, Y. Jiang, Q. Huang, S. Chen, F. Zhang, P. Tang and D. Li, Ind. Eng. Chem. Res., 2014, 53, 2287-2292.

33 Y. Zhao, G. Chen, T. Bian, C. Zhou, G. I. N. Waterhouse, L. Wu, C. Tung, L. J. Smith, D. O'Hare and T. Zhang, Adv. Mater., 2015, 27, 7824-7831.

34 R. M. M. Santos, J. Tronto, V. Briois and C. V. Santilli, J. Mater. Chem. A, 2017, 5, 9998-10009.

35 Q. Zhou and V. Verney, S. Commereuc, I. J. Chin and F. Leroux, J. Colloid Interface Sci., 2010, 349, 127-133.

36 L. Liu, M. Cheng and Z. Yang, Electrochim. Acta, 2018, 277, 67-76.

37 J. H. Yang, W. Zhang, H. Ryu, J. H. Lee, D. H. Park, J. Y. Choi, A. Vinu, A. A. Elzatahry and J. H. Choy, J. Mater. Chem. A, 2015, 3, 22730-22738.

38 D. W. Schaefer and R. S. Justice, Macromolecules, 2007, 40, 8501-8517.

39 P. J. Purohit, J. E. Huacuja-Sánchez, D. Y. Wang, F. Emmerling, A. Thünemann, G. Heinrich and A. Schönhals, Macromolecules, 2011, 44, 4342-4354.

40 G. Totaro, L. Sisti, A. Celli, I. Aloisio, D. Di Gioia, A. A. Marek, V. Verney and F. Leroux, Dalton Trans., 2018, 47, 3155-3165. 